\title{
Microstructural Evolution in 42SiCr Steel in a High-Temperature Chamber under Microscope Objective
}

\author{
Michal Peković ${ }^{1}$, Hana Jirková ${ }^{1}$, Kateřina Rubešová ${ }^{1}$, Tomáš Janda ${ }^{1}$, Radovan Bureš ${ }^{2}$ \\ ${ }^{1}$ Faculty of Mechanical Engineering - Regional Technological Institute, University of West Bohemia, \\ Univerzitní 8, 30614 Pilsen, Czech Republic \\ 2Institute of Materials Research, Slovak Academy of Science, Watsonova 47, 04001 Košice, Slovak Republic \\ E-mail: pekovicm@rti.zcu.cz, hstankov@rti.zcu.cz, krubesov@rti.zcu.cz, jandat@rti.zcu.cz, , rbures@saske.sk
}

Thanks to today's computer programs, engineers can derive a large amount of information from chemical composition of a material. This information includes phase transformation temperatures $\mathbf{A}_{\mathrm{cl}}, \mathbf{A}_{\mathrm{c} 3}, \mathbf{M}_{\mathrm{s}}$ and $\mathrm{M}_{\mathrm{f}}$. CCT and TTT diagrams for austenite decomposition can be determined as well. When steel is heated, austenite grains nucleate and grow in the initial microstructure. On cooling, the grains decompose into pearlite, ferrite, cementite and hardening phases. Transformations of this kind are thoroughly described in literature: the ways the individual phases form and the speed of their formation and temperatures involved. However, in-situ visual recordings of such transformations are relatively rare. With Linkam TS1400XY high-temperature stage and chamber integrated in an optical microscope, one can observe phase transformations in situ during heating and cooling. This paper explores microstructural evolution in $42 \mathrm{SiCr}$ steel in the course of heat treatment in a high-temperature chamber on an optical microscope stage which offers observation of changes in the material right under the microscope objective.

Keywords: high-temperature chamber, phase transformations, optical and electron microscopy, heat treatment

\section{Introduction}

Description of phase transformations and their temperatures is essential for designing effective heat treatment routes for steels. When chemical composition of the material is known, programs such as JMatPro and Thermocalc can provide a large amount additional information. This includes phase transformation temperatures and CCT and TT'T diagrams which characterize austenite decomposition [1]. A number of studies, not only theoretical ones, on phase transformations are available. They give description of formation of individual phases, and mechanisms of transformation and their characteristics in terms of exothermic or endothermic nature. However, in-situ visual recordings of such transformations are relatively rare. Today, they can be acquired using the TS1400XY high-temperature chamber from Linkam [2].

When placed under a microscope objective, the chamber enables observation of nucleation and growth of austenite grains as steel is heated to austenitizing temperature. The chamber provides a heating rate of $200^{\circ} \mathrm{C} / \mathrm{min}$ and a maximum temperature of $1400^{\circ} \mathrm{C}$. Specimens in the chamber can also be observed during cooling. The cooling rate is $200^{\circ} \mathrm{C} / \mathrm{min}$ as well. Cooling from austenitizing temperature causes various structural constituents to form, depending on the cooling rate. The heating and cooling processes are controlled through parameters entered either on the control panel of the chamber or via computer software [1]. The software also records the temperature- time plots. The chamber can be equipped with a Peltier module with a system of hoses for cooling the chamber components which are sensitive to high temperature. The chamber can be filled with protective atmosphere, such as nitrogen or argon (Fig. 1, left) [3, 4].

The chamber can be placed on the stage of an optical microscope. Microscope objectives with $10 \times$, $20 \times$ and $50 \times$ magnification were used for this investigation (Fig. 1, left). With their extended working distance, the objectives offer the focus needed for observing the specimen inside the chamber. The chamber contains a stage which can be moved in two perpendicular directions. Specimens can therefore be moved during treatment in order to find the right location for capturing an image or a video (Fig. 1 right) [4].

The maximum size of samples for the chamber is $5 \times 5 \mathrm{~mm}$ and their maximum possible thickness is 0.7 $\mathrm{mm}$. For a sharp image, the specimens need to be prepared as metallographic sections and the surface to be observed must be perpendicular to the objective axis. Inside the chamber, the specimen is placed on a ceramic plate on the microscope stage which slides to the position for heating and observation (Fig. 1, right). If the specimen is to be cooled rapidly, the plate can be withdrawn from the heating position. In such case however, the specimen cannot be observed under the microscope [5]. 


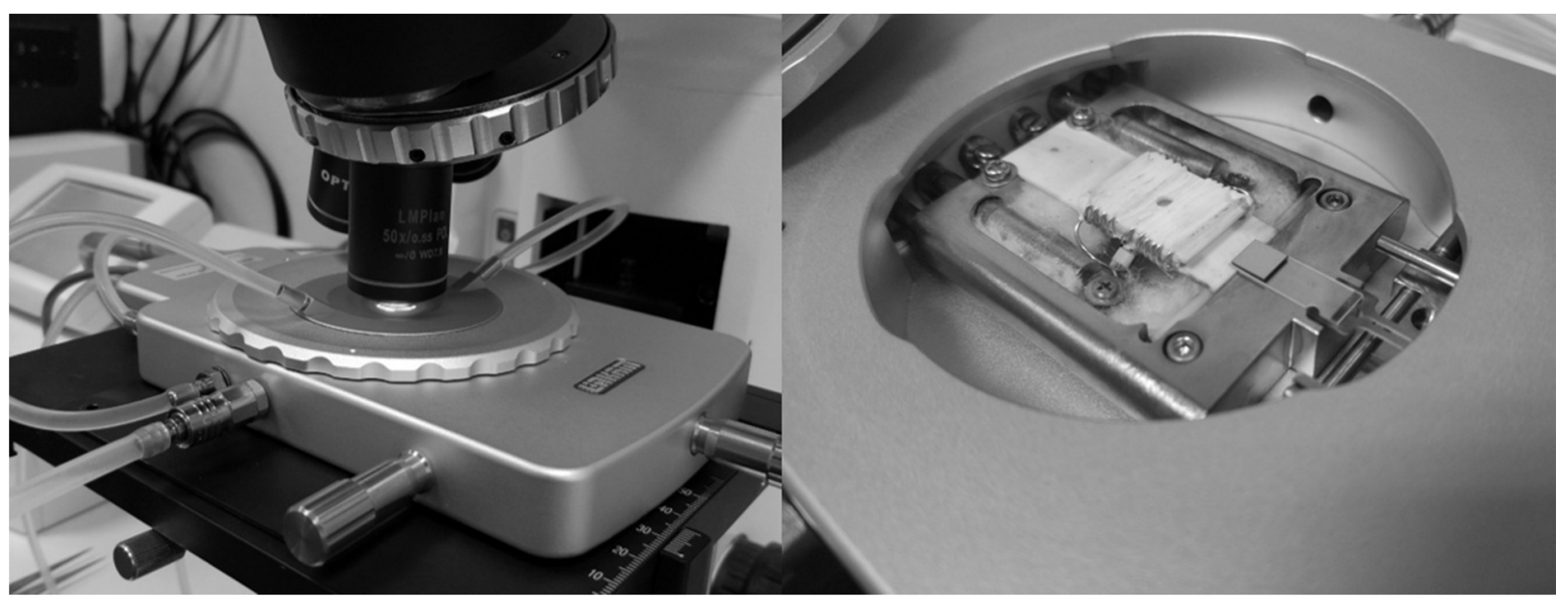

Fig. 1 The chamber during heating to higher temperatures (left), a view inside the chamber with a specimen on a ceramic glass (right) [4]

The high-temperature chamber is an excellent tool for exploring and understanding the processes which take place in high-strength steels in the course of their special heat treatments. A good example is the group of martensitic steels and their Q\&P processing. The typical feature of Q\&P (quenching and partitioning) processing is rapid cooling from the austenite region to between the Ms and Mf followed by reheating to a temperature around the Ms and holding. During the hold, retained austenite becomes stabilized by carbon which migrates from super-saturated martensite. Individual stages of the treatment are important to microstructural evolution and to mechanical properties of the product. This includes heating, which should produce homogeneous austenite at an appropriate temperature, and interrupted cooling between the Ms and Mf temperatures to achieve decomposition of a defined proportion of austenite to martensite. One of the available techniques for monitoring and gaining understanding of these processes is in-situ observation during heat treatment.

\section{Materials and methods}

The goal of this study was to observe phase transformations in 42SiCr steel (Tab. 1). It is a low-alloy medium-carbon steel with higher silicon and chromium levels. In the course of heating, formation of austenite was observed. Its decomposition and microstructural evolution were studied during the subsequent stages of treatment. Prior to the experiment, the right specimen preparation technique had to be identified for observation in the high-temperature chamber.

The heat treatment routes used in this study were Q\&P processing and austempering at an increased temperature. Another objective was to identify the difference between the evolution of microstructure at different holding temperatures (Fig. 2).

Tab. 1 Chemical composition of steel under investigation $[6]$

\begin{tabular}{|c|c|c|c|c|c|c|c|c|}
\hline & $\mathbf{C}$ & $\mathbf{S i}$ & $\mathbf{M n}$ & $\mathbf{C r}$ & $\mathbf{M o}$ & $\mathbf{N b}$ & $\mathbf{P}$ & $\mathbf{S}$ \\
\hline $\mathbf{4 2} \mathbf{S i C r}$ & 0.42 & 2.03 & 0.56 & 1.33 & 0.16 & 0.03 & 0.005 & 0.003 \\
\hline
\end{tabular}

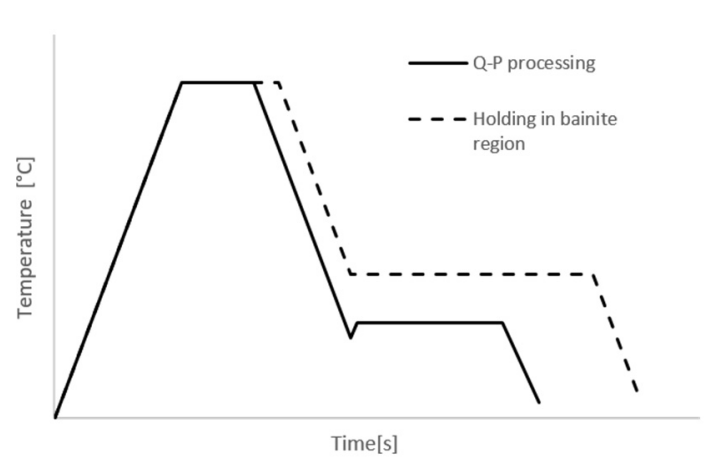

Fig. 2 Diagram of heat treatment route

\subsection{Sample preparation}

The samples for the high-temperature chamber were $4 \times 4 \mathrm{~mm}$ in size, with a thickness of $0.5 \mathrm{~mm}$. To obtain focused images of the microstructure, a great care was taken to make both faces of the specimens parallel. A grinding machine with a magnetic chuck was used for rough grinding. One of the specimen faces was then prepared by ordinary metallographic grinding and polishing.

In order to observe phase transformations in situ, the appropriate final preparation step had to be identified. Three methods were tested and compared. In the first one, a polishing cloth and $1 \mu \mathrm{m}$ suspension 
was employed. The second one involved polishing on a cloth and etching with 3\% nital. The third one was polishing with colloidal silica.

\subsection{Heat treating sequences}

Several trials were carried out before designing the experimental heat treatment sequences to find the optimal regime, temperatures and soaking times for full austenitization.

Two heat treatments of the $42 \mathrm{SiCr}$ steel were performed (Fig. 2). The Q\&P (quenching and partitioning) sequence comprised heating to $1050^{\circ} \mathrm{C}$ and soaking for $240 \mathrm{~s}$ with subsequent quenching to below the $\mathrm{M}_{\mathrm{s}}$. The final temperature in this stage is referred to as the quenching temperature (QT). The next step was reheating to above the partitioning temperature (PT) and holding at this temperature. Finally, the specimen was cooled to room temperature. The QT temperatures were $200^{\circ} \mathrm{C} / 250^{\circ} \mathrm{C} / 300^{\circ} \mathrm{C}$. Accordingly, there were three partitioning temperatures (PT): $250^{\circ} \mathrm{C} / 300^{\circ} \mathrm{C} / 350^{\circ} \mathrm{C}$. The holding time at $\mathrm{PT}$ was 5 minutes. The other heat treatment of $42 \mathrm{SiCr}$ was austempering which comprised holding at a temperature

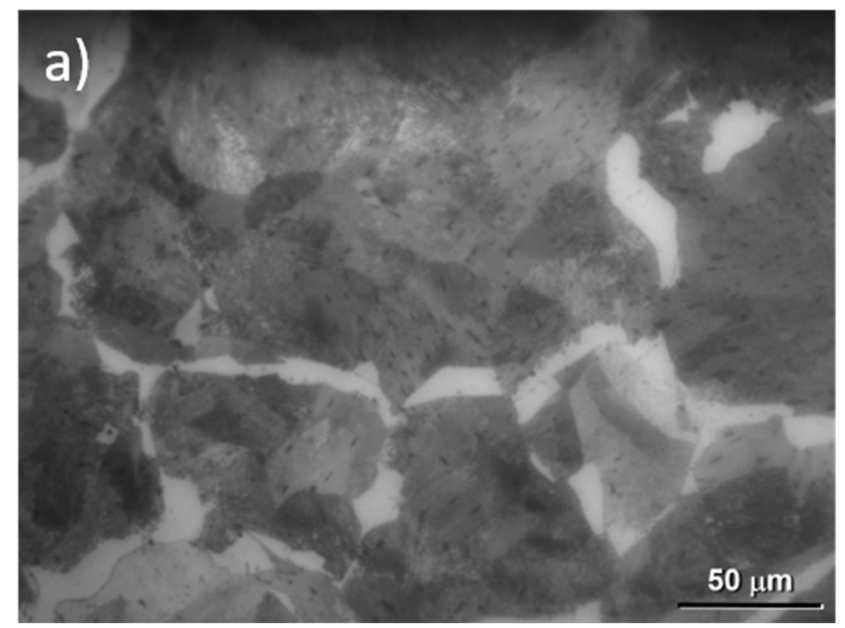

for bainitic transformation. The holding time was 10 minutes. The temperatures were $340^{\circ} \mathrm{C} / 380^{\circ} \mathrm{C} / 470^{\circ} \mathrm{C}$ (Fig. 2).

\section{Results and discussion}

Prior to the actual experiment, the optimal final specimen preparation step for observation was explored. Several trials showed that etching with 3\% nital is the best option. After etching, the initial microstructure became visible and its changes during heat treatment could be observed. Polishing with a polishing cloth and a $1 \mu \mathrm{m}$ suspension (without etching) proved ineffective because no changes were visible under the microscope. Polishing with colloidal silica only revealed grain boundaries [7].

In addition, it was found that high heating temperatures lead to rapid oxidation of the specimen surface. The oxide layer made observation of phase transformations impossible, particularly during isothermal holding and cooling to room temperature (RT). To prevent oxides from forming, the chamber was filled with argon for subsequent experiments [8].

Fig. 3 a) Initial microstructure of $42 \mathrm{SiCr}$ steel, b) Austenitic microstructure of $42 \mathrm{SiC}$ steel after holding for 3 minutes at $1050^{\circ} \mathrm{C}$

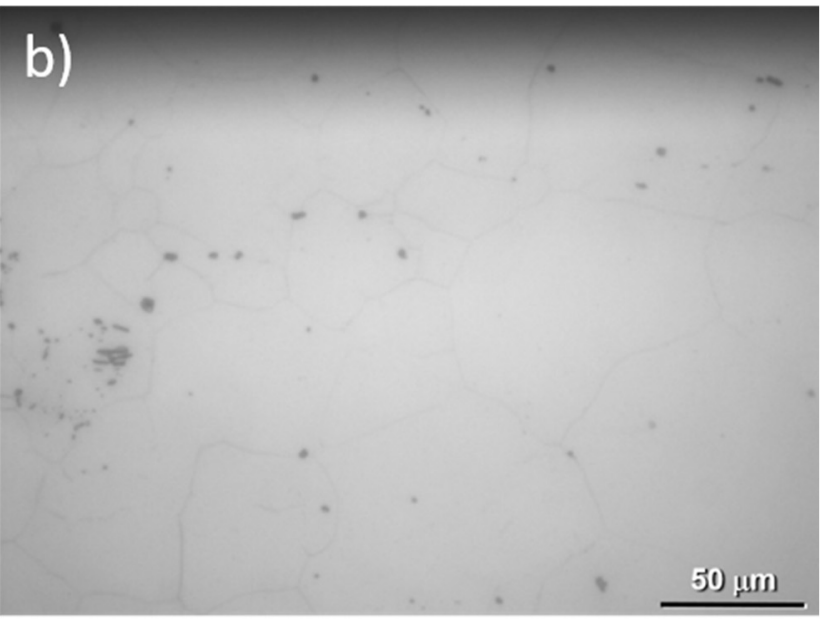

The initial microstructure of $42 \mathrm{SiCr}$ consisted of ferrite and pearlite (Fig. 3a). First, trials were carried out to find the temperature and time for full austenitization in the high-temperature chamber: $1050^{\circ} \mathrm{C}$ and
$240 \mathrm{~s}$, respectively. At this temperature, austenite grains with distinct boundaries were visible (Fig. 3b).
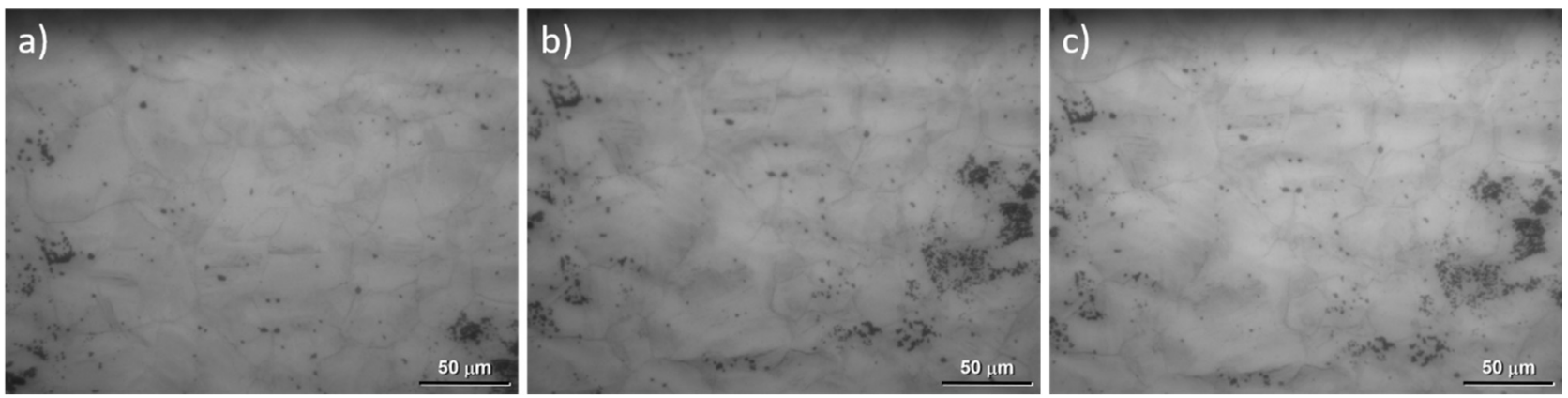

Fig. 4 Microstructure of $42 \mathrm{SiCr}$ steel in the course of $Q \otimes P$ processing: a) after cooling to $300^{\circ} \mathrm{C}$, b) at the end of partitioning at $200^{\circ} \mathrm{C}$, c) after final cooling [4] 
Then, the actual Q\&P process was performed. After soaking at austenitization temperature, the specimen was cooled at $200^{\circ} \mathrm{C} / \mathrm{min}$ to QT $\left(150^{\circ} \mathrm{C}, 200^{\circ} \mathrm{C}\right.$ and $250^{\circ} \mathrm{C}$ in the individual sequences). After cooling to QT, the specimen was reheated to PT which was $50^{\circ} \mathrm{C}$ higher. Fig. 4 presents micrographs of the material treated at $\mathrm{QT}=150^{\circ} \mathrm{C}$ and $\mathrm{PT}=200^{\circ} \mathrm{C}$. On cooling, austenite decomposition started at grain boundaries and advanced to the grain interior. This transforma- tion began at temperatures around $600^{\circ} \mathrm{C}$. The product was probably upper bainite, followed by lower bainite. At still lower temperatures, about $300^{\circ} \mathrm{C}$, dramatic changes in the microstructure took place with the first martensite needles forming in the material (Fig. 4a). Gradual transformation within individual grains was in progress and visible. While the specimen was held at the partitioning temperature (Fig. 4b) and cooled to room temperature (Fig. 4c), no appreciable changes were detected.
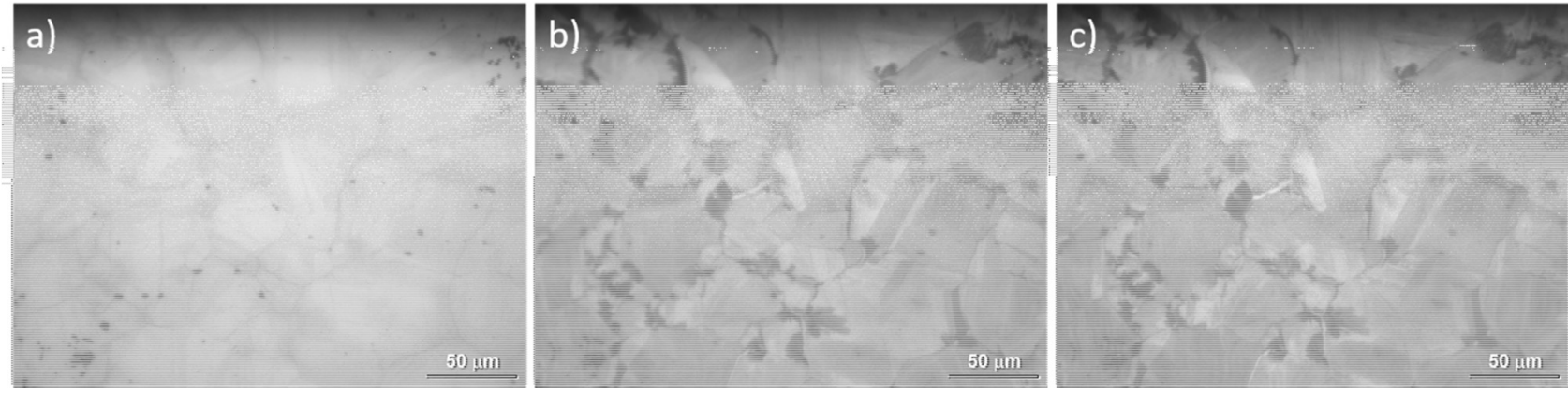

Fig. 5 Microstructure of $42 \mathrm{SiCr}$ steel during austempering: a) cooling to $365^{\circ} \mathrm{C}$, b) bolding at $340^{\circ} \mathrm{C} / 120 \mathrm{~s}$, c) bolding at $340^{\circ} \mathrm{C} / 600$ s

The initial microstructure for austempering consisted of ferrite and pearlite, as in the previous heat treatment. Austenitizing was performed at $1050^{\circ} \mathrm{C}$ for $240 \mathrm{~s}$. After austenitization, the steel was cooled again at $200^{\circ} \mathrm{C} / \mathrm{min}$ to three different isothermal holding temperatures. While the specimen was cooled, transformation to upper bainite was detected at $600^{\circ} \mathrm{C}$, starting at austenite grain boundaries. It was immediately followed by formation of lower bainite which continued during isothermal holding at both $340^{\circ} \mathrm{C}$ and $470^{\circ} \mathrm{C}$. Some austenite probably transformed to martensite during cooling to room temperature.

In the sequence with isothermal holding at $340^{\circ} \mathrm{C}$, even martensitic transformation was observed. Micrographs clearly show that in this sequence most austenite grains transform to martensite. Some grains also showed twinning. Figs. 5b, $5 \mathrm{c}$ are micrographs taken at the end of the hold at $340^{\circ} \mathrm{C}$ for $120 \mathrm{~s}$ and $600 \mathrm{~s}$,

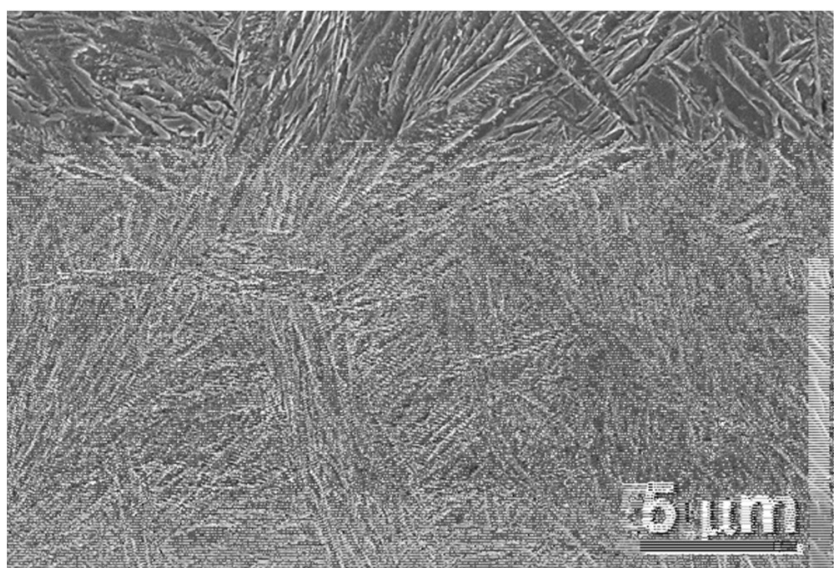

respectively. Upper bainite appears considerably darker than then other constituents. It is found mainly along prior austenite grains and at triple points. During final cooling to room temperature, no appreciable changes in the microstructure were detected using the optical microscope.

After heat treatment in the high-temperature chamber, all specimens were examined in a scanning electron microscope in order to benefit from the available large magnifications. The question was whether the products of phase transformations were bainite and martensite only or whether slow cooling led to formation of pearlite as well. Attention was paid to precipitation of fine carbides in bainite and along martensite needles. Metallographic sections were prepared using the conventional procedure and etched with nital in the same way as the sections for in-situ observation.

Fig. 6 Microstructure of $42 \mathrm{SiC}$ steel after Q\&P processing: left: QT $250^{\circ} \mathrm{C} / \mathrm{PT} 300^{\circ} \mathrm{C}$, right: QT $200^{\circ} \mathrm{C} / \mathrm{PT} 250^{\circ} \mathrm{C}$ 
The final microstructure after Q\&P processing at QT $250^{\circ} \mathrm{C} / \mathrm{PT} 300^{\circ} \mathrm{C}$ consisted of martensite and bainite with fine carbide precipitates (Fig. 6, left). Its hardness was $561 \mathrm{HV0.5}$ (Tab. 2). Treatment at QT $200^{\circ} \mathrm{C} / \mathrm{PT} 250^{\circ} \mathrm{C}$ led to a similar mixture of martensite and bainite with fine carbides (Fig. 6 right). There was less bainite than in the previous case. After this treatment, the hardness was 626 HV0.5 (Table 2). The last Q\&P sequence involved the temperatures QT $150^{\circ} \mathrm{C} / \mathrm{PT} 200^{\circ} \mathrm{C}$. The resulting microstructure was again a mixture of martensite and bainite with fine carbide precipitates. Bainite was in the minority and its sheaves were finer than in the previous specimens (Fig. 7 left). This specimen had a hardness of 590 HV0.5 (Tab. 2).

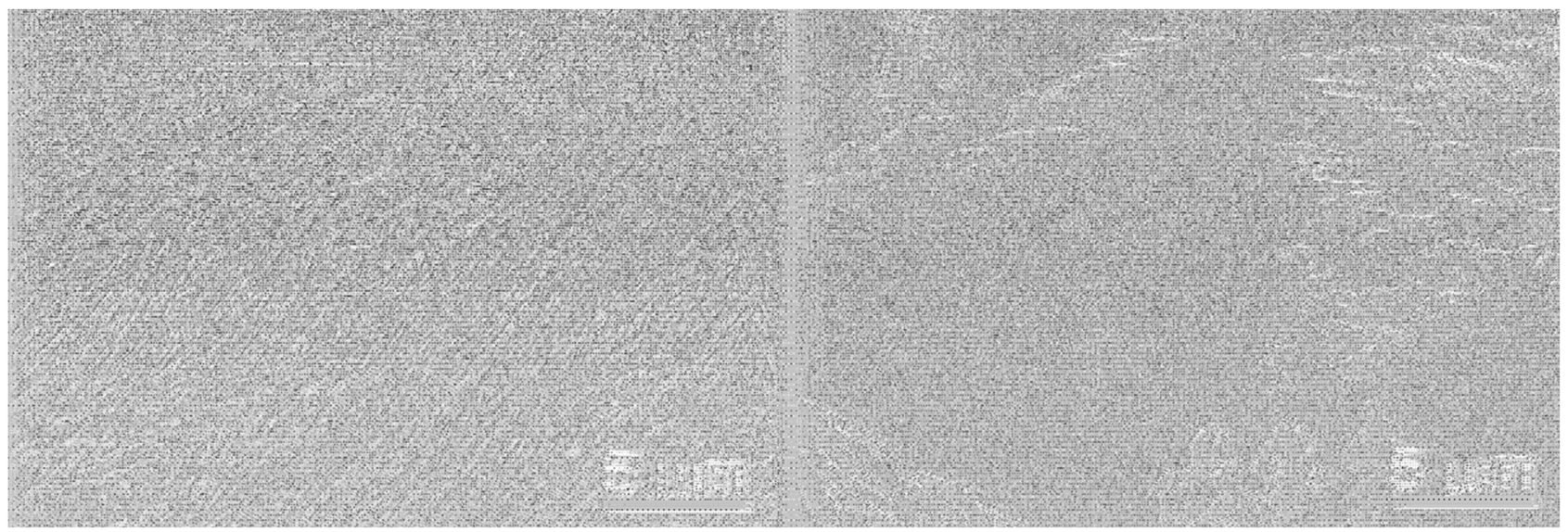

Fig. 7 Microstructure of $42 \mathrm{SiCr}$ steel after Q\&P processing: left: QT $150^{\circ} \mathrm{C} / \mathrm{PT} 200^{\circ} \mathrm{C}$, right: austempering with a hold at $470^{\circ} \mathrm{C}$

Observation of the austempered microstructure in a scanning electron microscope revealed that no pearlite had formed, not even during the sequence with holding at the highest temperature, $470^{\circ} \mathrm{C}$. After this treatment, the microstructure was a mixture of bainite and martensite (Fig. 7, right). The resulting hardness was 541 HV0.5 (Tab. 2). After the sequence which involved holding at a lower temperature, $380^{\circ} \mathrm{C}$, the

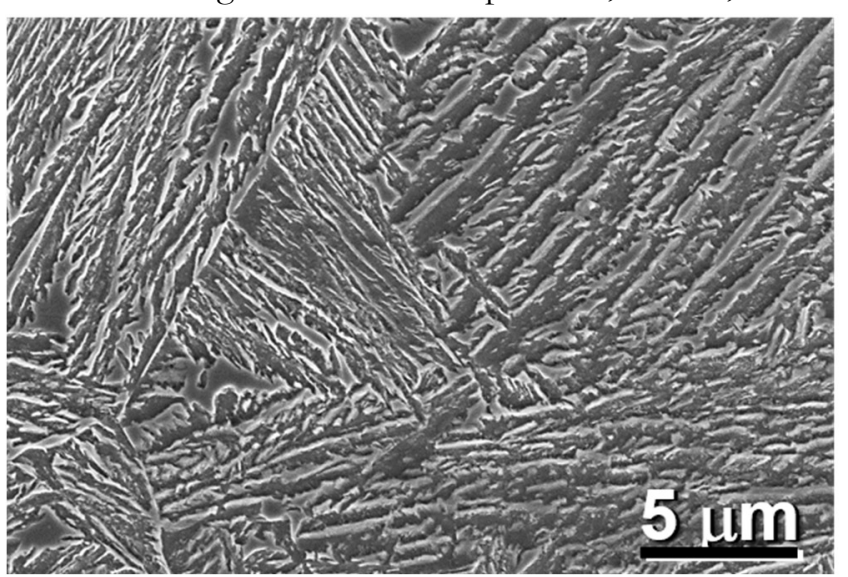

microstructure was dominated by bainitic ferrite sheaves. Its hardness was 460 HV10 (Fig. 8 left, (Tab. 2)). The sequence with an even lower holding temperature in the bainite transformation region, $340^{\circ} \mathrm{C}$, produced a mixture of martensite and bainite (Fig. 8, right). The amount of martensite was much higher than in the previous case, which was reflected in the hardness level: 660 HV10 (Tab. 2).

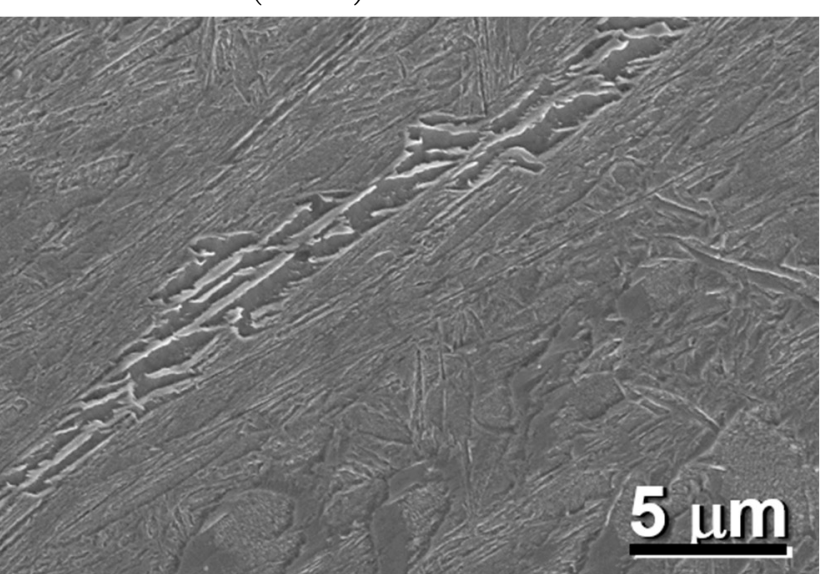

Fig. 8 Microstructure of $42 \mathrm{SiCr}$ steel after austempering with holding temperatures: $380^{\circ} \mathrm{Cleft,} 340^{\circ} \mathrm{C}$ right

Tab. 2 Hardness after heat treatment

\begin{tabular}{|c|c|c|c|}
\hline \multirow{4}{*}{ Q-P process } & QT $\left[{ }^{\circ} \mathrm{C}\right]$ & PT $\left[{ }^{\circ} \mathrm{C}\right] / \min$ & HV0.5 \\
\hline & 250 & $300 / 5$ & 561 \\
\hline & 200 & $250 / 5$ & 626 \\
\hline & 150 & $200 / 5$ & 590 \\
\hline \multirow{4}{*}{ Austempering } & \multicolumn{2}{|c|}{ Annealing $\left[{ }^{\circ} \mathrm{C}\right] / \mathrm{min}$} & \\
\hline & \multicolumn{2}{|c|}{$470 / 10$} & 541 \\
\hline & \multicolumn{2}{|c|}{$380 / 10$} & 460 \\
\hline & \multicolumn{2}{|c|}{$340 / 10$} & 660 \\
\hline
\end{tabular}


As follows from the above findings, in-situ observation in a high-temperature chamber should be complemented with observation in a scanning electron microscope. Although argon was used as protective gas in the high-temperature chamber, the etched surface of specimens does oxidize which can lead to misinterpretation of the image. After re-preparation, the microstructure can be observed without oxides, at higher magnification and in greater detail using scanning electron microscopy.

\section{Conclusions}

High-strength 42SiCr steel was heat treated in Linkam TS1400XY high-temperature chamber. The two heat treatment sequences were Q\&P processing and austempering.

As the material was brought to and held at austenitizing temperature, dissolution of pearlite and formation of austenite grains was observed. During cooling, which took place at $200^{\circ} \mathrm{C} / \mathrm{min}$, upper bainite was seen to form, starting at $600^{\circ} \mathrm{C}$. The recordings also show the growth of bainite from prior austenite grain boundaries. During Q\&P processing, step changes in the microstructure were observed under $300^{\circ} \mathrm{C}$. They probably involved the growth of martensite needles. While the steel was held isothermally in austempering sequences, the microstructure became darker and regions of dissimilar orientation developed in prior austenite grains.

The specimens heat-treated in the high-temperature chamber were then examined using optical and scanning electron microscopy. In Q\&P-processed specimens, the final microstructure was a mixture of martensite and bainite with fine carbide precipitates and a hardness around $600 \mathrm{HV} 10$, depending on the ration of bainite and martensite. Austempered microstructures were mixtures of martensite, bainite and dispersed ferrite. Their hardness was between 460 and $660 \mathrm{HV} 10$.

Using a high-temperature chamber integrated in an optical microscope enabled the behaviour of $42 \mathrm{SiCr}$ steel to be observed during two heat treatments. The findings can help clarify the processes taking place in individual stages of heat treatment.

\section{Acknowledgement}

The present contribution has been prepared under project LO1502 'Development of the Regional Technological Institute' under the auspices of the National Sustainability Programme I of the Ministry of Education of the Czech Republic aimed to support research, experimental development, and innovation.

\section{References}

[1] ESPOSITO, R., KLEBESZ, R., BARTOLI, O., KLYUKIN, Y., MONCADA, D., DOHERTY, A., BODNAR, R. (2012). Application of the Linkam TS1400XY heating stage to melt inclusion studies. In: Central European Journal of Geosciences., Vol. 4, pp. 208-218

[2] LEE, J., SHIBATA, K., ASAKURA, K., MASUMOTO, Y. (2002). Observation of $\gamma \rightarrow$ $\alpha$ Transformation in Ultralow-carbon Steel under a High Temperature Optical Microscope. In: ISIJ International. Vol. 42, No. 10, pp. 1135 1143

[3] LAMBERT-PERLADE, A., GOURGUES, A., PINEAU, A. (2004) Austenite to bainite phase transformation in the heat-affected zone of a high strength low alloy steel. In: Acta Materialia., Vol. 52, pp. 2337-2348

[4] PEKOVIĆ, M., OPATOVÁ, K., RUBEŠOVÁ, K., JANDA, T., JIRKOVÁ, H., BUREŠ, R. (2019) Observation of Phase Transformation in High-Temperature Chamber under Microscope Objetive Lens. In: Manufacturing Technology, Vol. 19, pp. 831-835, ISSN 1213-2489

[5] LISCHEWSKI, I., GOTTSTEIN, G. (2011) Nucleation and variant selection during the $\alpha-$ $\gamma-\alpha$ phase transformation in microalloyed steel. In: Acta Materialia., Vol. 59, pp. 1530-1541

[6] SENTE SOFTWARE LTD. (2017), JMatPro the Materials Property Simulation Package., Version 9.0., United Kingdom

[7] KUČEROVÁ, L., JIRKOVÁ. H, Š., KÁŇA, J. (2016). The Suitability of 42SiCr Steel for Quenching and Parti-tioning Process. In: Manufacturing Technology, Vol. 16, pp. 984-989. ISSN 12132489

[8] VOREL, I., JENÍČEK, Š., KÁŇA, J., IBRAHIM, K, KOTĚŠOVEC, V., (2016). Use of Optical and Electron Microscopy in Evaluating Optimization by Material-Technological Modelling of Manufacturing Processes In-volving Cooling of Forgings. In: Manufacturing Technology, Vol. 16, pp. 1383-1387, ISSN 1213 2489

[9] VANDER VOORT, G.(2004). Metallography and microstructures. In: ASM Handbook. ASM International, Vol. 9 